\title{
Lactic Acid Fermentation Improved Textural Behaviour, Phenolic Compounds and Antioxidant Activity of Chia (Salvia hispanica L.) Dough
}

\author{
Ana Yanina Bustos ${ }^{1,2 *}$, Carla Luciana Gerez ${ }^{3}$, Lina Goumana Mohtar Mohtar ${ }^{1}$, \\ Verónica Irene Paz Zanini ${ }^{4}$, Mónica Azucena Nazareno ${ }^{1}$, María Pía Taranto ${ }^{3}$ and \\ Laura Beatriz Iturriaga ${ }^{1}$ \\ ${ }^{1}$ Research and Transference Centre of Santiago del Estero (CITSE - CONICET - UNSE), RN9, \\ km 1125, AR-4206 Santiago del Estero, Argentina \\ ${ }^{2}$ San Pablo T University, Av. Solano Vera and Villa Nougués, AR-4129 Tucumán, Argentina \\ ${ }^{3}$ Reference Centre for Lactobacilli (CERELA-CONICET), Chacabuco 145, \\ AR-4000 San Miguel de Tucumán, Argentina \\ ${ }^{4}$ Institute of Bionanotechnology (INBIONATEC-CONICET), RN9, km 1125, \\ AR-4206 Santiago del Estero, Argentina \\ Received: December 29, 2016 \\ Accepted: May 16, 2017
}

\begin{abstract}
Summary
In this work, autochthonous lactic acid bacteria (LAB) were isolated from chia (Salvia hispanica L.) dough and selected on the basis of the kinetics of acidification and proteolytic activity. Strain no. C8, identified as Lactobacillus plantarum C8, was selected and used as starter to obtain chia sourdough. Lactic acid fermentation increased the organic acid mass fractions (lactic, acetic and phenyl lactic acids to $12.3 \mathrm{~g}, 1.0 \mathrm{~g}$ and $23.8 \mu \mathrm{g}$ per $\mathrm{kg}$ of dough respectively), and antioxidant activities, which increased by approx. 33-40\% compared to unfermented chia flour dough. In addition, total phenolic content increased $25 \%$ and its composition was strongly modified after $24 \mathrm{~h}$ of fermentation by L. plantarum C 8 . Chlorogenic acid was only found in the fermented dough $(2.5 \mathrm{mg} / \mathrm{g})$, while ferulic acid was detected from the beginning of fermentation, being $32 \%$ higher in chia sourdough $(5.6 \mathrm{mg} / \mathrm{g})$. The use of fermented chia sourdough improved the overall characteristics of white bread, including physical (e.g. reduced hardness and chewiness of the crumb) and antioxidant properties (25 $\%$ on average), compared to the white bread. These results indicate that the use of chia sourdough could be a promising alternative to improve the technological and antioxidant properties of wheat bread. In addition, this work has shown, for the first time, that lactic acid bacterium is able to ferment chia dough, improving its overall characteristics.
\end{abstract}

Key words: antioxidant activity, chia sourdough, Lactobacillus plantarum, phenolic compounds, physical properties

\section{Introduction}

Chia (Salvia hispanica L.) is an annual plant belonging to the Lamiaceae family and native to southern Mexico and northern Guatemala (1). Recently, due to its functional and nutritional attributes, scientists have revived their interest in chia. In fact, chia contains an important amount

\footnotetext{
*Corresponding author: Phone: +54 385423 8352; E-mail: abustos@uspt.edu.ar 
of vitamins, minerals, antioxidant compounds and polyunsaturated fatty acids, particularly the omega-3 and omega- 6 , which are found in the tissues of the central nervous system (2). Thus, the incorporation of chia in different foods such as pound cakes (3), wheat bread (4) and gluten-free bread (5) has recently been reported. However, despite its valuable nutritional and functional characteristics, the incorporation of chia in bakery products could adversely affect the gluten network and gas retention of dough, leading to low quality products $(4,6)$. Due to this undesired consequences, it is necessary to propose strategies that allow the enrichment of bakery products with this ingredient without detrimental technological effects.

Sourdough is a mixture of flour (principally rye and wheat flour) and water that is fermented with selected lactic acid bacteria (LAB). Numerous studies have reported positive effects of wheat and rye sourdough addition on bread quality (flavour, crumb structure, dough volume) and shelf life (7-10). Additionally, LAB fermentation can improve macromolecule hydrolysis, thus enhancing the digestibility and nutritional quality of bread $(11,12)$. Nevertheless, specific factors have to be controlled to reach an optimal fermentation process, with the type of flour and the lactic culture being the most relevant $(12,13)$. The flour affects the technological and nutritional quality of the baked products and the development of the microbial fermentation (13). Thus, the selection of a suitable starter strain allows a better utilization of particular flour (13). In this sense, to our knowledge, there are no data on sourdough prepared from chia flour and on the selection of adequate starter strains for preparation of sourdough bread. The aim of this work is to select autochthonous LAB strains to be used for chia sourdough fermentation. Then, rheological behaviour, organic acid production, phenolic compound content and antioxidant activity of chia sourdough made with the selected starter culture will be evaluated and used to supplement wheat bread. A technological and functional profile analysis of bread will be carried out to compare the advantages of the sourdough fermentation with respect to the use of unfermented chia flour.

\section{Materials and Methods}

\section{Materials}

Wheat flour and other ingredients were obtained on the local market in Santiago del Estero, Argentina, while commercial chia seeds were purchased from Sturla ${ }^{\circledR}$ (Buenos Aires, Argentina). Whole chia flour was obtained by milling the commercial chia seeds in a laboratory scale mill (Moulinex, Buenos Aires, Argentina), and a cascade sieve (model EJR 2000; Zonytest, Buenos Aires, Argentina) was used for the size fractionation of the flour. After sieving, the fraction that passed through the 20 mesh and was retained in 35 mesh (with particle size 580-840 $\mu \mathrm{m}$ ) was used for further studies because it was the major obtained fraction. The 1,1-diphenyl-2-picrylhydrazyl (DPPH), 2,4,6-Tris(2-pyridyl)-s-triazine (TPTZ), 6-hydroxy-2,5,7,8-tetramethyl-2-carboxylic acid (Trolox), ascorbic acid, gallic acid (GA), kaempferol, galangin, quercetin, and coumaric, benzoic, caffeic, ferulic, chlorogenic, dihydroxybenzoic, sulfuric and hydrochloric acids, sodium hydroxide, anhydrous petroleum ether, trichloroacetic acid, cycloheheximide, methanol, glycerol, sodium tetraborate and Folin Ciocalteu reagent were purchased from Sigma-Aldrich (St. Louis, MO, USA).

\section{Proximate analysis of flour}

Moisture content was quantified according to AOAC method (14) from the difference between the initial and final mass of the samples subjected to a temperature of $130{ }^{\circ} \mathrm{C}$. Proteins were determined by the Kjeldahl method (15). Briefly, the samples were digested in concentrated sulfuric acid with a catalyst, the nitrogen was converted to ammonium sulphate, and sodium hydroxide was added to release ammonia, which was distilled in standardized hydrochloric acid for quantification by titration. The protein content was calculated from total nitrogen using a factor of 5.7 for wheat and chia flour. For ash determination, the calcination in muffle furnace (KLS 30/11; Thermconcept, Bremen, Germany) at $500{ }^{\circ} \mathrm{C}$ was employed and the ash mass was calculated from the difference between the initial and final mass of the samples (16). For fat quantification, the Soxhlet method (16) was employed using anhydrous petroleum ether as solvent.

\section{Microbiological analysis and isolation of LAB}

$\mathrm{LAB}$ were isolated from chia flour naturally fermented at 30 or $37^{\circ} \mathrm{C}$ for $24 \mathrm{~h}$ with a dough yield $(Y)$ of 300 , calculated as follows:

$$
Y=(m(\text { dough }) / m(\text { flour })) \cdot 100
$$

Chia dough was made and propagated following a protocol commonly used for wheat flour sourdough, without the addition of starter cultures or baker's yeast (12). After this first fermentation, five refreshment steps were carried out by mixing $25 \%$ (by mass) of the previously fermented dough with flour and water $(Y=300)$, and incubating for $24 \mathrm{~h}$ at 30 or $37^{\circ} \mathrm{C}$. Samples for $\mathrm{pH}$ measurement were taken after fermentation and processed as follows: $10 \mathrm{~g}$ of each sample was blended with $90 \mathrm{~mL}$ of distilled water and mixed on a digital hot plate magnetic stirrer (model MS-H-Pro; Scilogex, LLC, Rocky Hill, CT, USA) and then the mixture was centrifuged at $9000 \times g$ (model Z 326 K; Hermle Labortechnik, Wehingen, Germany) for $15 \mathrm{~min}$. The $\mathrm{pH}$ was measured in the supernatant using a $\mathrm{pH}$ meter ( $\mathrm{pH}$ 209; Hanna Instruments, Póvoa de Varzim, Portugal). After five refreshments, the acidification rate was stable, and fermented chia dough was used for presumptive LAB isolation as follows: $10 \mathrm{~g}$ of chia dough was homogenized with $90 \mathrm{~mL}$ of sterile saline solution and cultivated in MRS agar (Sigma-Aldrich) supplemented with cycloheximide $(0.1 \mathrm{~g} / \mathrm{L})$. Plates were incubated at 30 or $37^{\circ} \mathrm{C}$ for $48 \mathrm{~h}$. Autochthonous bacteria were randomly selected from the plates containing between 30 and 300 colonies. Individual colonies were purified by scratching on MRS agar plates. Pure cultures were stored at $-70{ }^{\circ} \mathrm{C}$ in MRS broth with $15 \%$ (by mass per volume) glycerol for further examination. Fifty presumptive LAB selected (Gram-positive, catalase-negative, non-motile rods and cocci, and able to acidify the culture medium) were cultivated in MRS broth at 30 or $37^{\circ} \mathrm{C}$ (depend- 
ing on the isolation temperature) for $24 \mathrm{~h}$. Cells were harvested by centrifugation (4000×g for 10 min; model $\mathrm{Z}$ $326 \mathrm{~K}$; Hermle Labortechnik) and washed twice with saline solution. Chia flour $(100 \mathrm{~g})$ and $200 \mathrm{~mL}$ of tap water, containing the above cellular suspension (cell density in the dough of $7 \mathrm{CFU} / \mathrm{g}$ ) were used to give an $Y=300$. Dough samples were fermented at 30 or $37^{\circ} \mathrm{C}$ for $24 \mathrm{~h}$, according to the optimal growth temperature of the lactic strains. $\mathrm{LAB}$ growth was determined by the plate dilution method using MRS agar, the plates were incubated at 30 or 37 ${ }^{\circ} \mathrm{C}$ for $48 \mathrm{~h}$, and the results were expressed as log CFU/g. The $\mathrm{pH}$ of the dough was determined as described above, and the concentrations of total free amino acids in the dough samples were determined using the $o$-phthalaldehyde (OPA) method (17). Briefly, $0.5 \mathrm{~g}$ of dough were blended with $2 \mathrm{~mL}$ of $0.75 \mathrm{M}$ of trichloroacetic acid, homogenized and kept at $4{ }^{\circ} \mathrm{C}$ for $30 \mathrm{~min}$. Afterwards, the samples were centrifuged $(9000 \times g, 1 \mathrm{~min}$, model Z $326 \mathrm{~K}$; Hermle Labortechnik) and $10 \mu \mathrm{L}$ of supernatant were blended with $200 \mu \mathrm{L}$ of OPA reagent $(10.75 \mathrm{~mL}$ of distilled water, $1.25 \mathrm{~mL}$ of $20 \%$ (by mass per volume) SDS, $12.5 \mathrm{~mL}$ of sodium tetraborate, $50 \mathrm{~mL}$ of $\beta$-mercaptoethanol and $20 \mathrm{mg}$ of OPA dissolved in $500 \mu \mathrm{L}$ of methanol). The reaction mix was kept at room temperature for $5 \mathrm{~min}$ and absorbance was determined at $340 \mathrm{~nm}$ using the UV-Vis spectrophotometer Jasco V-630 (Medson, Paczkowo, Poland). Calibration curve was plotted using the glutamic acid standard in the range of 0.2 to $5.0 \mathrm{mM}$.

\section{Genotypic identification of selected $L A B$}

The genotypic identification of the selected strain was determined on the basis of sequencing of the variable (V1) region of the $16 \mathrm{~S} \mathrm{rDNA}$, as previously described (18). The oligonucleotides for PCR reactions were: PLB16, 5'-AGAGTTTGATCCTGGCTCAG-3', and MLB16, 5'-GGCTGCTGGCACGTAGTTAG-3'. PCR amplification consisted of 30 cycles for $30 \mathrm{~s}$ at $94^{\circ} \mathrm{C}, 30 \mathrm{~s}$ at $50^{\circ} \mathrm{C}$ and $1 \mathrm{~min}$ at $72^{\circ} \mathrm{C}$. Final PCR products were purified using a commercial kit (AccuPrep ${ }^{\circledR}$ PCR Purification Kit; Bioneer Corporation, Genbiotech, Buenos Aires, Argentina) and subjected to sequencing (Sequencing Service, Science and Technology Center, CONICET, Tucumán, Argentina). The resulting sequences were analysed on-line using the NCBI BLAST algorithms (19) and the Ribosomal Database Project (20).

\section{Preparation of chia sourdough with the selected starter}

Chia sourdough was prepared using the selected strain, L. plantarum C8. Sourdough was fermented at 37 ${ }^{\circ} \mathrm{C}$ for $24 \mathrm{~h}$. LAB growth, sourdough preparation and $\mathrm{pH}$ determination were carried out identically as described above, except for fermentation, which was performed at $37^{\circ} \mathrm{C}$ (optimal growth temperature of the selected strain). Lactic acid quantification was performed by amperometry using an electrochemical system of three glassy carbon electrodes ( $3 \mathrm{~mm}$; CH Instruments, Inc., Austin, TX, USA) optimized for the detection of lactic acid, as previously reported (21). Acetic and phenyllactic (PLA) acids were measured as previously described (10) by HPLC (model 2350; ISCO, Lincoln, NE, USA) using an Aminex HPX-87H ion-exclusion column $(300 \mathrm{~mm} \times 7.8 \mathrm{~mm}$; Bio-Rad, Hercules, CA, USA). Organic acid mass fractions were expressed in $\mathrm{g}$ or $\mu \mathrm{g}$ per $\mathrm{kg}$ of dough.

\section{Fundamental rheological measurements of chia sourdough}

A controlled stress rheometer (AR 2000; TA Instruments, New Castle, DE, USA) was used for the dynamic rheological assays. The control software Rheology Advantage Data Analysis Program (22) was used to obtain directly the data of storage modulus $\left(G^{\prime}\right)$, loss modulus $\left(G^{\prime \prime}\right)$, complex modulus $\left(G^{*}\right)$, and the tangent of loss angle $(\tan \delta)$. The dough samples (0 and $24 \mathrm{~h}$ of fermentation) were fixed between the plates $(d=40 \mathrm{~mm}$ with a gap of 1.5 $\mathrm{mm}$ ), the overlaying dough was removed, and the measurements started after $10 \mathrm{~min}$. A solvent trap device (TA Instruments) was used to avoid the sample evaporation during the measurement. Frequency sweeps were performed using a strain value in the linear viscoelastic region and a frequency range of $0.1-10 \mathrm{~Hz}$ at $25^{\circ} \mathrm{C}$. A Peltier plate system (TA Instruments) attached was used to control temperature.

\section{Total phenolic compounds and antioxidant activity of chia sourdough}

\section{Extract preparation}

Ten $\mathrm{g}$ of chia dough (at 0 and $24 \mathrm{~h}$ of fermentation) and bread were dried at $50{ }^{\circ} \mathrm{C}$ for $12 \mathrm{~h}$ (model TDC70; Tecnodalvo S.R.L., Santa Fe, Argentina), then manually crumbled and ground in a traditional stone mortar to obtain dust samples. For extraction, $1 \mathrm{~g}$ of powder sample of dough (2.4\% moisture) and bread (5.3\% moisture) was blended with $10 \mathrm{~mL}$ of $80 \%$ (by volume) aqueous methanol solution for $2 \mathrm{~h}$ at room temperature. Samples were afterwards centrifuged $(9000 \times g$ for $15 \mathrm{~min}$, model Z $326 \mathrm{~K}$; Hermle Labortechnik). The supernatants (extracts) were stored at $-20^{\circ} \mathrm{C}$ until use.

Total phenolic compounds and their identification by capillary zone electrophoresis

Total phenolic contents were determined colorimetrically using Folin-Ciocalteu reagent, as previously described by Ezekiel et al. (23). Absorbance of the mixture was determined at $725 \mathrm{~nm}$ using the spectrophotometer UV-Vis Jasco V-630 (Medson). Calibration method was used to determine the phenolic compound concentration by means of the calibration plot performed with GA in the concentration range of 0.09 to $12 \mathrm{mmol} / \mathrm{L}$. Results were expressed in mg of gallic acid equivalents (GAE) per $g$.

The identification of phenolic compounds present in the dough (at 0 and $24 \mathrm{~h}$ of fermentation) was performed by capillary zone electrophoresis on Agilent Capillary Electrophoresis System G1601A (Agilent Technologies Deutschland $\mathrm{GmbH}$ \& Co. KG, Waldbronn, Germany) equipped with a UV detector set at $206 \mathrm{~nm}$. Separation and analysis were carried out on an uncoated fused silica capillary tubing $(50 \mu \mathrm{m}$ i.d. and $56 \mathrm{~cm}$ total length; Agilent Technologies) at $25{ }^{\circ} \mathrm{C}$. The operating buffer was composed of sodium tetraborate, $25 \mathrm{mM}$, pH=9.0. Kaempferol, galangin, quercetin, and coumaric, benzoic, caffeic, ferulic, chlorogenic and dihydroxybenzoic acids were used as standards.

\section{Antioxidant activity}

Antioxidant activity (AA) of the dough and bread extracts was determined based on the DPPH method (24). 
Different aliquots of each extract (prepared as described above) were added to methanolic solution of DPPH (initial absorbance $A_{515 \mathrm{~nm}}=1.20$ ). The decrease in the absorbance was monitored during $30 \mathrm{~min}$ using a UV-Vis spectrophotometer Jasco V-630; Medson). AA (\%) was calculated according to the following equation:

$$
\mathrm{AA}=\left(\left(1-A_{\mathrm{S}}\right) / A_{0}\right) \cdot 100
$$

where $A_{\mathrm{S}}$ is the absorbance of the solution in a steady state and $A_{0}$ is the absorbance of the DPPH solution prior to the addition of the sample. The absorbance of the system at the steady state was estimated by mathematical fitting of kinetic curves using GraphPad Prism version 5.00 for Windows (25). The $\mathrm{IC}_{50}$ values indicate the concentration of the sample required to decrease the absorbance at $515 \mathrm{~nm}$ by $50 \%$.

Ferric reducing ability of plasma assay

The ferric reducing ability of plasma (FRAP) assay was carried out according to Benzie and Strain (26). To each reaction, $0.05 \mathrm{~mL}$ of the extract, prepared as described above, was added to $0.95 \mathrm{~mL}$ of the reagent mixture, shaken vigorously and allowed to stand at room temperature in the dark for $20 \mathrm{~min}$. Afterwards, absorbance was measured, and the final results were expressed in $\mu \mathrm{g}$ of Trolox equivalents (TE) per $\mathrm{g}$.

\section{Wheat bread preparation using chia sourdough}

Chia sourdough fermented by L. plantarum C8 was used for the production of wheat bread. The different formulations are listed in Table 1. Traditional bread from wheat flour and wheat bread containing chia flour were manufactured and used as the controls. Commercial dry yeast S. cerevisiae (Calsa, Yeast Company S.A., Buenos Aires, Argentina) was used as leavening agent for all dough types (7 log CFU per $\mathrm{g}$ of dough). The following baking schedule was adopted: mixing for $10 \mathrm{~min}$ (first $2 \mathrm{~min}$ at slow speed and $8 \mathrm{~min}$ at increased speed). The dough samples were individually placed in aluminium pans and fermented at $(30 \pm 1){ }^{\circ} \mathrm{C}$ and $85 \%$ of relative humidity for $60 \mathrm{~min}$. After fermentation, the dough was baked in a batch oven $\left(180{ }^{\circ} \mathrm{C}\right.$ for $20 \mathrm{~min}$, model OD-38D; BLU Tec, Buenos Aires, Argentina), and the bread loaves were cooled at room temperature for $120 \mathrm{~min}$. The bread loaves were packed in polyethylene bags and stored at $30{ }^{\circ} \mathrm{C}$.

Table 1. Mass fractions of ingredients in different bread loaves

\begin{tabular}{lccc}
\hline \multirow{2}{*}{ Ingredient } & \multicolumn{3}{c}{$w / \%$} \\
\cline { 2 - 4 } & WB & WB-CF & WB-CS \\
\hline Wheat flour & 100 & 80 & 80 \\
Chia flour & - & 20 & - \\
Chia sourdough & & - & 40 \\
NaCl & 2 & 2 & 2 \\
S. cerevisiae & 3 & 3 & 3 \\
Water & 55 & 55 & 35 \\
\hline
\end{tabular}

$\mathrm{WB}=$ wheat bread, $\mathrm{WB}-\mathrm{CF}=$ wheat bread with unfermented chia flour, WB-CS=wheat bread with chia sourdough. The wheat/chia flour ratio was 4:1 in both formulations
Specific loaf volume measurement and the texture profile analysis were carried out $2 \mathrm{~h}$ after baking. Loaf volumes were measured by the rapeseed displacement method (3). Specific loaf volumes were calculated by dividing the loaf volume by the loaf mass, and the results were expressed in $\mathrm{mL} / \mathrm{g}$. The texture profile was determined using the universal testing machine TA.XTplus Texture Analyzer (Stable Micro Systems, Godalming, UK) and following a procedure reported previously (6) with some modifications. A double compression test was applied, and a 20-mm diameter cylinder probe (TA-11) was employed. Samples were prepared by cutting 2-cm high slices, allowing only crumb texture measurements. Bread slices were compressed to $50 \%$ of their original height. The textural parameters reported were: firmness (g), chewiness (g) and cohesiveness.

\section{Data analysis}

All measurements were conducted in at least three independent assays, and the obtained results were reported as mean values with their respective standard deviations. The analysis of variance (ANOVA) and Fisher's least significant difference (LSD) post-hoc tests were performed using InfoStat (27). All statistical analyses were conducted at a significance level of $\mathrm{p}<0.05$.

\section{Results and Discussion}

\section{Proximate composition of flour}

First, in order to characterize the raw material used in this work, the proximate composition of chia and wheat flour was determined. Protein $((25.1 \pm 2.1) \%$ by mass $)$, ash $((6.7 \pm 0.2) \%$ by mass) and fat ((19.4 \pm 1.5$) \%$ by mass) contents in chia flour were higher than in wheat flour ((14.6 \pm 1.1$),(0.7 \pm 0.3)$ and $(1.6 \pm 0.1) \%$ by mass, respectively). These results are consistent with previous reports: $9-23 \%$ of proteins and $25-35 \%$ of lipids (3). It was reported that chia seeds from Argentina are mainly (60-70 $\%)$ composed of linolenic acid (28), whose consumption was related to beneficial effects on human health (2). These data indicate that the addition of chia flour to wheat bread could dramatically improve its protein and fat content. Furthermore, the high ash level of chia flour makes it a good supplement to wheat flour.

\section{Isolation and selection of $L A B$ from chia sourdough}

In order to select a starter to be used for chia dough fermentation, autochthonous LAB strains were isolated from chia sourdough. Fifty strains (33 cocci and 17 lactobacilli) able to acidify the MRS broth, Gram-positive, catalase-negative and non-motile, were presumptively classified as LAB. Lactobacilli are usually selected as sourdough starters mainly due to their competitiveness and adaptation to this particular environment; thus 17 lactobacilli were further selected to be inoculated in chia sourdough. The acidification capacity $(\Delta \mathrm{pH})$ and total free amino acid values of the fermented chia sourdough were taken into account for the final selection. Before fermentation, the $\mathrm{pH}$ of the dough was $(6.3 \pm 0.1)$. The 17 strains decreased the $\mathrm{pH}$ of the dough with $\Delta \mathrm{pH}$ values (difference between 
the $\mathrm{pH}$ before and after fermentation) ranging from $(1.50 \pm 0.05)$ to $(2.0 \pm 0.1)$. The initial concentration of total free amino acids was $(9.2 \pm 0.5) \mu \mathrm{M}$ per $\mathrm{g}$ of dough, while the final concentration ranged from $(19.5 \pm 0.9)$ to $(28.3 \pm 1.1)$ $\mu \mathrm{M}$ per $\mathrm{g}$ of dough. The highest $\Delta \mathrm{pH}$ value (2.0) and total free amino acid concentration $((28.3 \pm 1.1) \mu \mathrm{M}$ per $\mathrm{g}$ of dough) were observed in the dough fermented by C8 strain, which was further genotypically identified as Lactobacillus plantarum C8 and used as single starter for sourdough preparation.

\section{Selected chia sourdough starter}

Chia flour was fermented by L. plantarum $\mathrm{C} 8$ to obtain sourdough. After $24 \mathrm{~h}$ of fermentation, cell counts of $9.2 \mathrm{CFU} / \mathrm{g}$ and final $\mathrm{pH}=4.3$ were reached. The $\mathrm{pH}$ decrease was associated with the production of organic acids. In fact, a gradual increase in lactic acid was observed during the fermentation, reaching a value of $12.3 \mathrm{~g}$ per $\mathrm{kg}$ dough after $24 \mathrm{~h}$ (Fig. 1). Additionally, acetic acid (1.0 g per $\mathrm{kg}$ of dough) and PLA (23.8 $\mu \mathrm{g}$ per $\mathrm{kg}$ of dough) were also detected in chia sourdough (at $24 \mathrm{~h}$ ) (data not shown). PLA is an antimicrobial agent produced by some strains of LAB able to prevent fungal spoilage (10). At the end of fermentation, the value of fermentation quotient, given by the lactic/acetic acid ratio was 12 . This value is in the range of those previously reported for sourdough made with quinoa and rye $(12,29)$.

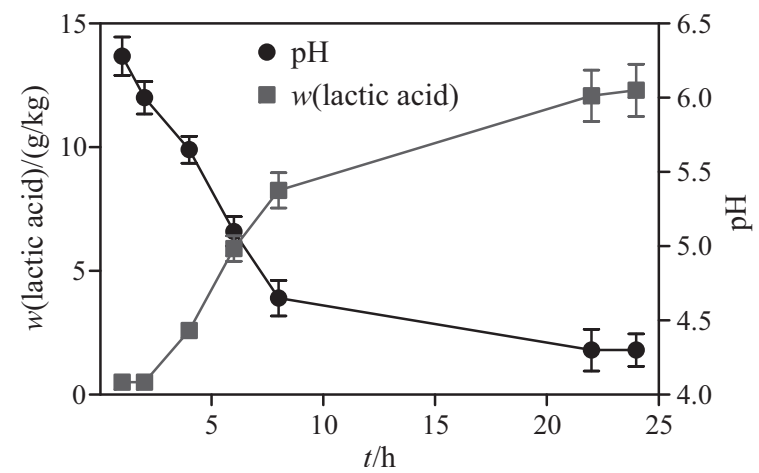

Fig. 1. Mass fraction of lactic acid and $\mathrm{pH}$ of chia sourdough inoculated with Lactobacillus plantarum C8 for $24 \mathrm{~h}$

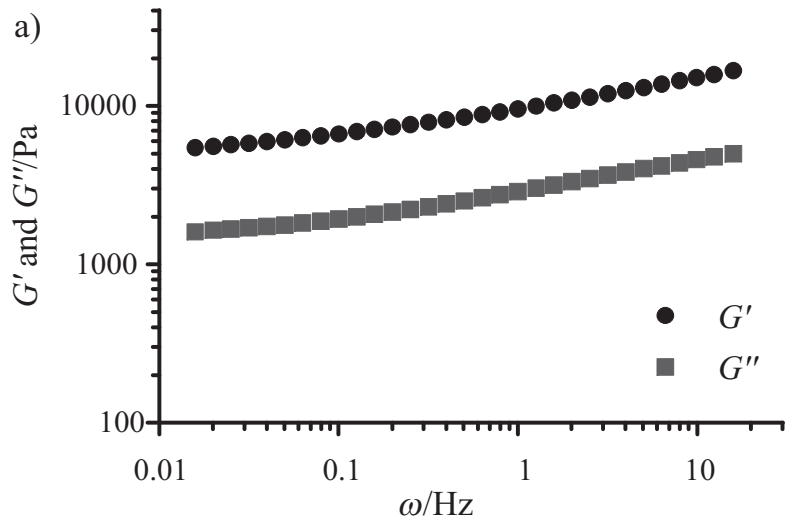

\section{Oscillatory testing of chia sourdoughs}

Fig. 2 shows the frequency sweeps corresponding to the chia sourdough at the beginning and the end of fermentation. The oscillatory frequency sweeps carried out in the linear viscoelastic domain indicate that storage, loss and complex moduli had an increasing trend in all the frequency range applied, and a solid-like behaviour was also predominant $\left(G^{\prime}>G^{\prime \prime}\right)$ in both studied samples. $G^{*}$ showed differences between the samples; unfermented sourdough showed the highest values at the frequency of $1 \mathrm{~Hz}((9149 \pm 819) \mathrm{Pa})$, while after $24 \mathrm{~h}$ of fermentation, it reached a value of $(6902 \pm 420) \mathrm{Pa}$ (data not shown). The spectrum analysis suggests that the fermentation of chia caused a loss of consistency and an increase in the viscous character with respect to that of the unfermented dough (at $0 \mathrm{~h}$ ). A similar effect on the rheological properties of dough made with chestnut and chia flour following hydrocolloid addition was reported (5). In addition, a decrease in the complex shear modulus and elasticity of amaranth sourdough made with L. plantarum or L. paralimentarius strains and buckwheat sourdough prepared with L. plantarum, L. brevis or L. paralimentarius strains was reported $(30,31)$. These rheological changes could be partially attributed to the increase in the proteolytic activity observed in chia dough after fermentation by C8 strain, as was previously reported for wheat and rye sourdough $(7,9)$. However, chemically acidified dough (wheat or amaranth, among others) showed the opposite behaviour, resulting in more elastic dough, probably because the acidification is instantaneous and not progressive as in the sourdough process, and in this way, microbial and flour enzymes are not activated $(30,32)$.

\section{Phenolic compounds and total antioxidant activities of chia sourdough}

The presence of phenolic compounds in the diet is beneficial to health mainly due to their antioxidant activities $(2,33)$. As shown in Table 2, the total phenolic content significantly increased (from 14.90 to $20.80 \mathrm{mg}$ GAE per $\mathrm{g}$ ) in chia sourdough after $24 \mathrm{~h}$ of fermentation. In order to identify the phenolic compounds present in the fermented and unfermented chia dough, capillary electrophoresis was performed (Fig. 3). The phenolic content and

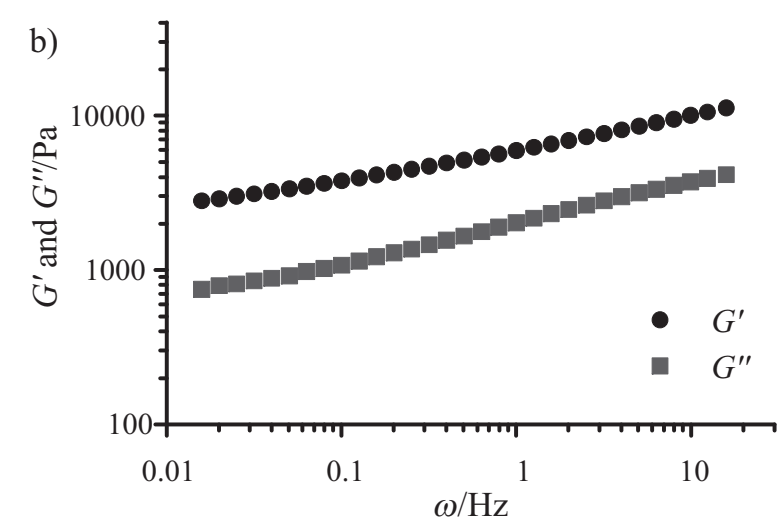

Fig. 2. Storage modulus $\left(G^{\prime}\right)$ and loss modulus $\left(G^{\prime \prime}\right)$ vs. frequency $(\omega)$ for chia sourdough at: a) the beginning and b) after $24 \mathrm{~h}$ of fermentation 
Table 2. Total phenolic content and antioxidant activities of the sourdough and bread loaves

\begin{tabular}{|c|c|c|c|c|}
\hline \multirow{3}{*}{ Sample } & \multirow{3}{*}{$\frac{\gamma(\text { phenolics as GAE })}{\mathrm{mg} / \mathrm{g}}$} & \multicolumn{3}{|c|}{ Antioxidant activity } \\
\hline & & \multicolumn{2}{|c|}{ DPPH } & \multirow{2}{*}{$\mathrm{FRAP}$ (as TE)/(mg/g) } \\
\hline & & $\mathrm{IC}_{50} /(\mathrm{mg} / \mathrm{mL})$ & $\mathrm{AA} / \%$ & \\
\hline \multicolumn{5}{|c|}{ Chia sourdough } \\
\hline \multicolumn{5}{|l|}{$t / \mathrm{h}$} \\
\hline 0 & $(14.90 \pm 0.05)^{\mathrm{a}}$ & $(3.1 \pm 3.7)^{\mathrm{a}}$ & $(52.0 \pm 2.1)^{\mathrm{a}}$ & $(14.1 \pm 1.8)^{\mathrm{a}}$ \\
\hline 24 & $(20.80 \pm 0.09)^{\mathrm{b}}$ & $(2.0 \pm 5.5)^{\mathrm{b}}$ & $(85.9 \pm 4.0)^{\mathrm{b}}$ & $(21.1 \pm 3.3)^{\mathrm{b}}$ \\
\hline$\overline{W B}$ & n.d. & $(72.1 \pm 10.5)^{c}$ & $(1.75 \pm 0.04)^{c}$ & $(0.5 \pm 0.05)^{c}$ \\
\hline WB-CF & $(0.63 \pm 0.03)^{\mathrm{c}}$ & $(16.3 \pm 1.0)^{\mathrm{d}}$ & $(8.3 \pm 0.4)^{\mathrm{d}}$ & $(2.8 \pm 0.9)^{\mathrm{d}}$ \\
\hline WB-CS & $(1.13 \pm 0.08)^{\mathrm{d}}$ & $(12.1 \pm 0.6)^{\mathrm{e}}$ & $(11.0 \pm 0.6)^{\mathrm{e}}$ & $(3.7 \pm 0.1)^{\mathrm{e}}$ \\
\hline
\end{tabular}

$\mathrm{GAE}=$ gallic acid equivalent, $\mathrm{AA}=$ antioxidant activity against $\mathrm{DPPH}, \mathrm{TE}=$ Trolox equivalent, $\mathrm{WB}=$ wheat bread, $\mathrm{WB}-\mathrm{CF}=$ wheat bread with unfermented chia flour, WB-CS=wheat bread with chia sourdough, n.d.=not detected; variables with the same letter in superscript in the same column are not significantly different $(\mathrm{p}<0.05)$

profile of chia sourdough (at 0 and $24 \mathrm{~h}$ of fermentation) were strongly modified by lactic acid fermentation, as was observed in the electropherograms. In fact, 14 compounds were modified, out of which nine had higher concentrations and five showed the opposite behaviour after fermentation. Although we investigated the presence of coumaric, benzoic, caffeic, ferulic, chlorogenic and dihydroxybenzoic acids as well as of kaempferol, galangin and quercetin, compounds previously reported in chia products $(2,34)$, only two (ferulic and chlorogenic acids) compounds coincided with the tested standards (Fig. 3). Chlorogenic acid was only found after lactic acid fermenta-
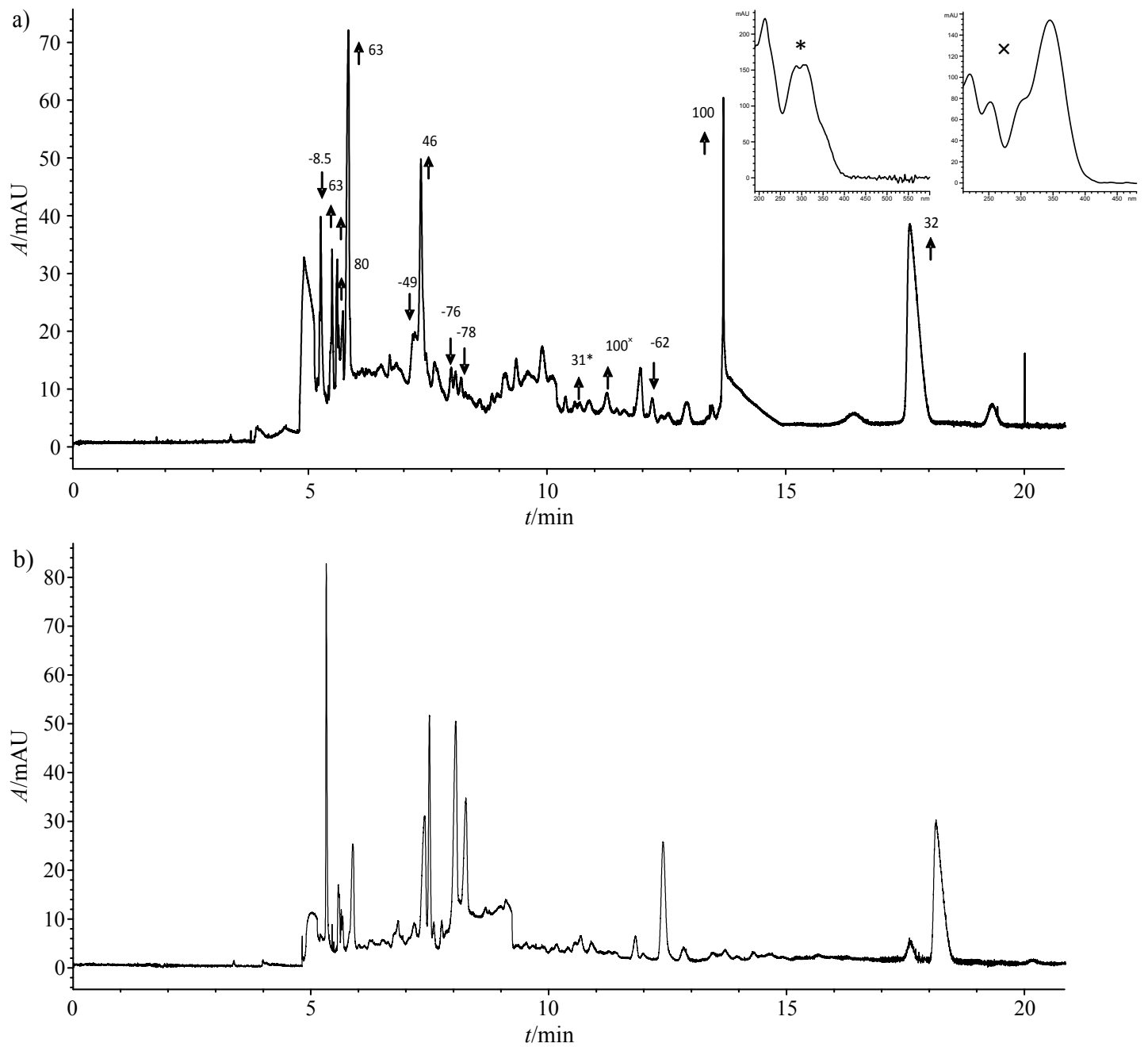

Fig. 3. Electropherograms of: a) fermented chia sourdough, and b) unfermented dough. Each arrow corresponds to a peak whose area was modified and the percentage of change is indicated above. ${ }^{*}$ ferulic acid, ${ }^{\times}$chlorogenic acid 
tion $(2.5 \mathrm{mg} / \mathrm{g})$, while ferulic acid increased from $3.9 \mathrm{mg} / \mathrm{g}$ in unfermented dough to $5.6 \mathrm{mg} / \mathrm{g}$ in 24 -hour fermented sourdough.

The increase of phenolic compounds by lactic acid fermentation was also observed in cereals such as rye, barley and oat, and in a variety of vegetables (e.g. cucumbers, cabbages, olives, carrots, French beans, marrows, artichokes, capers and eggplants) (33,35). In this work, 1.33-fold increase of total phenolic acids during lactic fermentation and 1.44-fold increase of ferulic acid were observed. Konopka et al. (36) reported that in whole meal and white wheat and rye sourdough (prepared with $L$. casei and $L$. brevis) 1.0 to $13.5 \%$ of bound ferulic acid was released after fermentation. Hole et al. (33) showed that the bioavailability of the dietary phenolic acids in the flour from whole grain barley and oat groat significantly improved after fermentation with LAB. In fact, the highest increments of 27.4- and 25.3-fold were observed in whole grain barley and oat groat, respectively, fermented with three probiotic strains (L. johnsonii LA1, L.reuteri SD2112 and L. acidophilus LA-5). Remarkably, L. plantarum is the LAB strain most frequently isolated from niches where phenolic compounds are abundant, and its ability to metabolize them has been reported $(37,38)$. During sourdough fermentation, esterase activities of LAB and flour endogenous enzymes are able to hydrolyse the complex phenolic compounds and their glycosylated forms into free phenolic acids $(37,39)$.

The antioxidant activity of chia sourdough was also evaluated (Table 2). The activity of the extract of chia sourdough on DPPH followed first-order kinetics, the fermented dough showing the highest antioxidant effectiveness (Fig. 4). By both complementary methods employed, the antioxidant activity after $24 \mathrm{~h}$ of fermentation increased from 33.3 to $39.6 \%$ with respect to the initial values (Table 2). In fact, the activity of the sourdough, determined by the DPPH radical scavenging (AA and $\mathrm{IC}_{50}$ ), reached $85.9 \%\left(\mathrm{IC}_{50}=2.0 \mathrm{mg} / \mathrm{mL}\right)$, while at the beginning of the fermentation it was $52 \%\left(\mathrm{IC}_{50}=3.1 \mathrm{mg} / \mathrm{mL}\right)$. The $\mathrm{IC}_{50}$ found in our study is in line with that reported by Scapin et al. (24) in chia seed extract. Similar trend was observed with the FRAP method; the antioxidant activity improved from 14.1 to $21.1 \mathrm{mg}$ of TE per $\mathrm{g}$ after fermentation. Other authors $(13,29)$ also reported an increase in the antioxidant activity in sourdough prepared from different types of flour such as rye, whole wheat and spelt, among others,

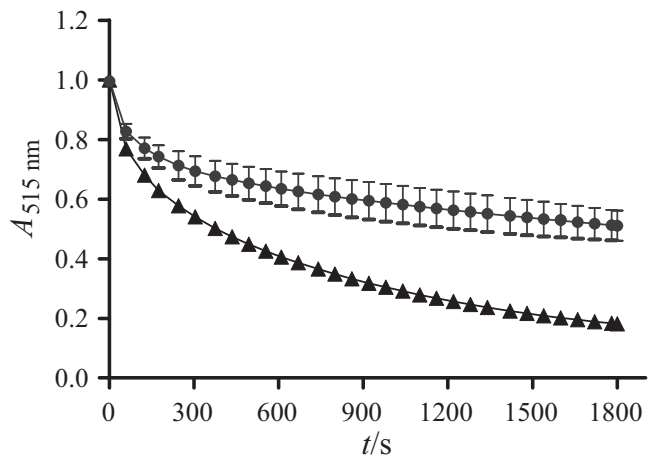

Fig. 4. Kinetic curves of DPPH scavenging of extracts of sourdough at $0 \mathrm{~h}$ (dots) and after $24 \mathrm{~h}$ of fermentation (triangles) with respect to that of the unfermented dough and additionally demonstrated the capacity of LAB to release antioxidant peptides through the proteolysis of native cereal proteins.

\section{Bread evaluation tests}

Chia sourdough prepared with L. plantarum C8 was used for the production of wheat bread, while the wheat bread loaves with and without chia flour were used as controls. In accordance with the above results, the highest phenolic content $(1.13 \mathrm{mg} / \mathrm{g})$ was found in the wheat bread with chia sourdough (Table 2). Its antioxidant activity was 1.3 times higher than of the bread with chia flour and 7 times greater than in wheat bread. Therefore, sourdough addition effectively improved the mass fraction of phenols and antioxidant activity of traditional bread.

Specific volumes of the different types of bread are listed in Table 3. Chia flour or sourdough addition slightly reduced the specific volume of the loaves compared to wheat bread. Similar behaviour was observed in the bread containing 5 to $11 \%$ (by mass) of chia flour $(4,6)$. As reported previously, the addition of chia decreased the amount of gluten present in the formulation and consequently reduced the retention of air bubbles in the dough (6). On the other hand, the utilization of wheat sourdough has been reported both to decrease and increase the bread volume (32). It has been suggested that the influence of the sourdough on bread volume is due mainly to the enzymatic reactions that develop during fermentation, since the $\mathrm{pH}$ gradually drops, allowing the activation of amylolytic and proteolytic enzymes, among others, to modify the dough components.

Table 3. Effect of chia flour and sourdough addition on the specific loaf volume $(v)$ and texture parameters of bread loaves

\begin{tabular}{lcccc}
\hline \multirow{2}{*}{ Sample } & \multirow{2}{*}{$v /(\mathrm{mL} / \mathrm{g})$} & \multicolumn{3}{c}{ Texture analysis profile } \\
\cline { 3 - 5 } & & Firmness/g & Chewiness/g & Cohesiveness \\
\hline WB & $(3.3 \pm 0.23)^{\mathrm{a}}$ & $(1815 \pm 66)^{\mathrm{a}}$ & $(1150 \pm 139)^{\mathrm{a}}$ & $(0.8 \pm 0.03)^{\mathrm{a}}$ \\
WB-CF & $(2.7 \pm 0.30)^{\mathrm{b}}$ & $(1324 \pm 225)^{\mathrm{b}}$ & $(1050 \pm 280)^{\mathrm{a}}$ & $(1.3 \pm 0.07)^{\mathrm{b}}$ \\
WB-CS & $(2.9 \pm 0.19)^{\mathrm{b}}$ & $(966 \pm 147)^{\mathrm{c}}$ & $(605 \pm 80)^{\mathrm{b}}$ & $(1.3 \pm 0.05)^{\mathrm{b}}$ \\
\hline
\end{tabular}

$\mathrm{WB}=$ wheat bread, $\mathrm{WB}-\mathrm{CF}=$ wheat bread with unfermented chia flour, WB-CS=wheat bread with chia sourdough; variables with the same letter in superscript in the same column are not significantly different $(\mathrm{p}<0.05)$

The addition of chia sourdough reduced the firmness and chewiness of the crumb with respect to that of wheat bread. The decrease in firmness could be explained by the rheological behaviour previously described (Fig. 1), where the lower values of storage module $\left(G^{\prime}\right)$ of sourdough than of unfermented dough could decrease bread firmness. In this sense, a decrease in chewiness and firmness had previously been reported when smaller amount of buckwheat sourdough was added to the bread (30). On the contrary, other authors observed the opposite behaviour in chia bread (4).

Cohesiveness is a textural parameter that is linked to the integration of components of a sample when it is sub- 
jected to deformation. In both the wheat bread with chia sourdough and the wheat bread with chia flour, an important increase of cohesiveness with respect to that of wheat bread was observed, without significant differences between them.

\section{Conclusions}

Recently, chia flour has been studied due to its nutritional and functional characteristics, and its incorporation in different foods is frequently reported. Chia sourdough fermented by a selected Lactobacillus plantarum strain was characterized. After $24 \mathrm{~h}$ of lactic acid fermentation, a loss of consistency and an increase in the viscous character were observed. Additionally, phenolic compound concentration and antioxidant activity were enhanced by lactic acid fermentation. Finally, the use of this chia sourdough improved the overall characteristics of traditional wheat bread, including its physical and antioxidant properties, which were even better than those observed in the bread with unfermented chia flour.

\section{Acknowledgements}

This research was supported by grants from National University of Santiago de Estero and National Scientific and Technical Research Council (CONICET) (PIO-CONICET 14520140100005CO), National Agency for Scientific and Technological Promotion (PICT 393), and San Pablo T University, Argentina (IC-502).

\section{References}

1. Álvarez-Chávez LM, Valdivia-López MA, Aburto-Juárez ML, Tecante A. Chemical characterization of the lipid fraction of Mexican chia seed (Salvia hispanica L.). Int J Food Prop. 2008;11:687-97.

https://doi.org/10.1080/10942910701622656

2. Reyes-Caudillo E, Tecante A, Valdivia-López MA. Dietary fibre content and antioxidant activity of phenolic compounds present in Mexican chia (Salvia hispanica L.) seeds. Food Chem. 2008;107:656-63.

https://doi.org/10.1016/j.foodchem.2007.08.062

3. Pizarro PL, Lopes Almeida E, Sammán NC, Chang YK. Evaluation of whole chia (Salvia hispanica L.) flour and hydrogenated vegetable fat in pound cake. LWT - Food Sci Technol. 2013;54:73-9.

https://doi.org/10.1016/j.lwt.2013.04.017

4. Coelho MS, Salas-Mellado MM. Effects of substituting chia (Salvia hispanica L.) flour or seeds for wheat flour on the quality of the bread. LWT - Food Sci Technol. 2015;60:72936.

https://doi.org/10.1016/j.lwt.2014.10.033

5. Moreira R, Chenlo F, Torres MD. Effect of chia (Sativa hispanica L.) and hydrocolloids on the rheology of gluten-free doughs based on chestnut flour. LWT - Food Sci Technol. 2013;50:160-6. https://doi.org/10.1016/j.lwt.2012.06.008

6. Steffolani E, Martinez MM, León AE, Gómez M. Effect of pre-hydration of chia (Salvia hispanica L.), seeds and flour on the quality of wheat flour breads. LWT - Food Sci Technol. 2015;61:401-6. https://doi.org/10.1016/j.lwt.2014.12.056

7. Clarke CI, Schober TJ, Dockery P, O'Sullivan K, Arendt EK. Wheat sourdough fermentation: effects of time and acidifica- tion on fundamental rheological properties. Cereal Chem. 2004;81:409-17. https://doi.org/10.1094/CCHEM.2004.81.3.409

8. Mamhoud A, Nionelli L, Bouzaine T, Hamdi M, Gobbetti M, Rizzello CG. Selection of lactic acid bacteria isolated from Tunisian cereals and exploitation of the use as starters for sourdough fermentation. Int J Food Microbiol. 2016;225:919.

https://doi.org/10.1016/j.ijfoodmicro.2016.03.004

9. Thiele C, Gänzle MG, Vogel RF. Contribution of sourdough lactobacilli, yeast, and cereal enzymes to the generation of amino acids in dough relevant for bread flavor. Cereal Chem. 2002;79:45-51. https://doi.org/10.1094/CCHEM.2002.79.1.45

10. Gerez CL, Torino MG, Obregozo MD, Font de Valdez G. A ready-to-use antifungal starter culture improves the shelf life of packaged bread. J Food Protect. 2010;73:758-62. https://doi.org/10.4315/0362-028X-73.4.758

11. Bartkiene E, Juodeikiene G, Vidmantiene D. Nutritional quality of fermented defatted soya and flaxseed flours and their effect on texture and sensory characteristics of wheat sourdough bread. Int J Food Sci Nutr. 2012;63:722-9. https://doi.org/10.3109/09637486.2011.649248

12. Rizzello CG, Lorusso A, Montemurro M, Gobbetti M. Use of sourdough made with quinoa (Chenopodium quinoa) flour and autochthonous selected lactic acid bacteria for enhancing the nutritional, textural and sensory features of white bread. Food Microbiol. 2016;56:1-13. https://doi.org/10.1016/j.fm.2015.11.018

13. Coda R, Di Cagno R, Gobbetti M, Rizzello CG. Sourdough lactic acid bacteria: exploration of non-wheat cereal-based fermentation. Food Microbiol. 2014;37:51-8. https://doi.org/10.1016/j.fm.2013.06.018

14. AOAC Official Methods of Analysis. Determination of moisture content. Rockville, MD, USA: AOAC International; 1990.

15. Kjeldahl J. A new method for the determination of nitrogen in organic matter. Z Anal Chem. 1883;22:366-82. https://doi.org/10.1007/BF01338151

16. Horwitz W. Evaluation of analytical methods used for regulation of foods and drugs. Anal Chem. 1982;54:67-76. https://doi.org/10.1021/ac00238a002

17. Church FC, Porter DH, Catignani GL, Swaisgood HE. An o-phthalaldehyde spectrophotometric assay for proteinases. Anal Biochem. 1985;146:343-8. https://doi.org/10.1016/0003-2697(85)90549-4

18. Hébert EM, Raya RR, Tailliez P, de Giori GS. Characterization of natural isolates of Lactobacillus strains to be used as starter cultures in dairy fermentation. Int J Food Microbiol. 2000;59:19-27. https://doi.org/10.1016/S0168-1605(00)00282-8

19. Zhang Z, Schwartz S, Wagner L, Miller W. A greedy algorithm for aligning DNA sequences. J Comput Biol. 2000;7: 203-14. https://doi.org/10.1089/10665270050081478

20. Cole JR, Wang Q, Fish JA, Chai B, McGarrell DM, Sun Y, et al. Ribosomal Database Project: data and tools for high throughput rRNA analysis. Nucleic Acids Res. 2014;42:D633-42. https://doi.org/10.1093/nar/gkt1244

21. Zanini VP, López de Mishima B, Solís V. An amperometric biosensor based on lactate oxidase immobilized in laponitechitosan hydrogel on a glassy carbon electrode. Application to the analysis of L-lactate in food samples. Sensor Actuat B-Chem. 2011;155:75-80.

https://doi.org/10.1016/j.snb.2010.11.026

22. Rheology Advantage Data Analysis, v. 4.1.1.33073, TA Instruments, New Castle, DE, USA; 2016. Available from: http:// www.tainstruments.com. 
23. Ezekiel R, Singh N, Sharma S, Kaur A. Beneficial phytochemicals in potato-a review. Food Res Int. 2013;50:487-96. https://doi.org/10.1016/j.foodres.2011.04.025

24. Scapin G, Schmidt MM, Prestes RC, Rosa CS. Phenolics compounds, flavonoids and antioxidant activity of chia seed extracts (Salvia hispanica) obtained by different extraction conditions. IFRJ. 2016;23:2341-6.

25. Swift ML. GraphPad Prism, data analysis, and scientific graphing. J Chem Inf Comput Sci. 1997;37:411-2. https://doi.org/10.1021/ci960402j

26. Benzie IFF, Strain JJ. The ferric reducing ability of plasma (FRAP) as a measure of 'antioxidant power': the FRAP assay. Anal Biochem. 1996;239:70-6. https://doi.org/10.1006/abio.1996.0292

27. Di Rienzo J, Casanoves F, Balzarini M, Gonzalez L, Tablada M, Robledo CW. InfoStat v. 2011. Cordoba, Argentina: Faculty of Agriculture, National University of Cordoba; 2011. Avaible from http://www.infostat.com.ar.

28. Ixtaina VY, Nolasco SM, Tomás MC. Physical properties of chia (Salvia hispanica L.) seeds. Ind Crop Prod. 2008;28:286-93. https://doi.org/10.1016/j.indcrop.2008.03.009

29. Banu I, Aprodu I. Studies concerning the use of Lactobacillus helveticus and Kluyveromyces marxianus for rye sourdough fermentation. Eur Food Res Technol. 2012;234:769-77. https://doi.org/10.1007/s00217-012-1691-1

30. Houben A, Götz H, Mitzscherling M, Becker T. Modification of the rheological behavior of amaranth (Amaranthus hypochondriacus) dough. J Cereal Sci. 2010;51:350-6. https://doi.org/10.1016/j.jcs.2010.02.003

31. Moroni AV, Dal Bello F, Zannini E, Arendt EK. Impact of sourdough on buckwheat flour, batter and bread: biochemical, rheological and textural insights. J Cereal Sci. 2011;54:195-202. https://doi.org/10.1016/j.jcs.2011.04.008

32. Katina K. Sourdough: a tool for the improved flavour, texture and shelf-life of wheat bread. Espoo, Finland: VTT Publications; 2005.
33. Hole AS, Rud I, Grimmer S, Sigl S, Narvhus J, Sahlstrøm S. Improved bioavailability of dietary phenolic acids in whole grain barley and oat groat following fermentation with probiotic Lactobacillus acidophilus, Lactobacillus johnsonii, and Lactobacillus reuteri. J Agric Food Chem. 2012;60:6369-75. https://doi.org/10.1021/jf300410h

34. Capitani MI, Ixtaina VY, Nolasco SM, Tomás MC. Microstructure, chemical composition and mucilage exudation of chia (Salvia hispanica L.) nutlets from Argentina. J Agric Food Chem. 2013;93:3856-62. https://doi.org/10.1002/jsfa.6327

35. Katina K, Liukkonen KH, Kaukovirta Norja A, Adlercreutz $\mathrm{H}$, Heinonen SM, Lampi AM, et al. Fermentation-induced changes in the nutritional value of native or germinated rye. J Cereal Sci. 2007;46:348-55. https://doi.org/10.1016/j.jcs.2007.07.006

36. Konopka I, Tańska M, Faron A, Czaplicki S. Release of free ferulic acid and changes in antioxidant properties during the wheat and rye bread making process. Food Sci Biotechnol. 2014;23:831-40 https://doi.org/10.1007/s10068-014-0112-6

37. Rodríguez H, Curiel JA, Landete JM, de las Rivas B, de Felipe FL, Gómez-Cordovés $C$, et al. Food phenolics and lactic acid bacteria. Int J Food Microbiol. 2009;132:79-90. https://doi.org/10.1016/j.ijfoodmicro.2009.03.025

38. Curiel JA, Rodríguez H, Landete JM, de las Rivas B, Muñoz R. Ability of Lactobacillus brevis strains to degrade food phenolic acids. Food Chem. 2010;120:225-9. https://doi.org/10.1016/j.foodchem.2009.10.012

39. Nionelli L, Curri N, Curiel JA, Di Cagno R, Pontonio E, Cavoski I, et al. Exploitation of Albanian wheat cultivars: characterization of the flours and lactic acid bacteria microbiota, and selection of starters for sourdough fermentation. Food Microbiol. 2014;44:96-107. https://doi.org/10.1016/j.fm.2014.05.011 